\title{
PROGRESSIVE PARALYSIS AFTER BILATERAL FACET DISLOCATION OF THE CERVICAL SPINE
}

\author{
Y. J. MAHALE, J. R. SILVER
}

From the National Spinal Injuries Centre, Stoke Mandeville

\begin{abstract}
We report 13 patients with missed bilateral facet dislocation of the lower cervical spine who subsequently developed severe spinal-cord involvement. There were more women and the patients were older than in most groups with spinal injury. The commonest cause was a fall, and paralysis appeared from six to $\mathbf{4 8}$ hours after injury in most patients. Ten patients made some recovery after late reduction but three remained totally paralysed.
\end{abstract}

We discuss the pathogenesis of the late cord lesion and the reasons for delay in diagnosis.

Bilateral facet dislocation of the cervical spine is usually associated with severe paralysis, and rarely occurs without significant cord involvement. Immediate reduction of the dislocation is conventional practice (Walton 1893; Evans 1961; Shrosbree 1979) since an increase in paralysis may occur after delay (Beatson 1963; Braakman and Penning 1971). Such delay is relatively rare, but we report a retrospective study of 13 patients, and discuss the pathogenesis of immediate and late spinal-cord involvement and the reasons for delay in diagnosis.

\section{PATIENTS AND METHODS}

We reviewed the medical records of all patients admitted to the National Spinal Injuries Centre (NSIC) with dislocations of the cervical spine between 1944 and 1990 . Only 13 out of 341 patients with dislocations of the middle or lower cervical spine had suffered the delayed onset of paralysis. Their initial radiographs were reviewed to determine their adequacy at showing the whole of the cervical spine. The type of dislocation, associated fractures and any degenerative changes were also noted. The amount of anterior subluxation was measured, and the sagittal diameter of the spinal canal at the level of dislocation was determined from post-reduction lateral films.

Y. J. Mahale, MS Orth, Senior House Officer

J. R. Silver, FRCP Ed, FRCP, Consultant in Spinal Injuries

National Spinal Injuries Centre, Stoke Mandeville Hospital, Mandeville Road, Aylesbury, Bucks HP21 8AL, England.

Correspondence should be sent to Dr J. R. Silver.

(C) 1992 British Editorial Society of Bone and Joint Surgery $0301-620 X / 92 / 2325 \$ 2.00$

J Bone Joint Surg [Br] 1992; 74-B:219-23.

\section{RESULTS}

All 13 patients had been initially managed at other hospitals and transferred to the NSIC after the development of paralysis. There were seven men and six women. Nine were over 40 years of age. The cause of injury was a fall in eight, a road-traffic accident in four, and a sporting accident in one. Nine patients had a hyperflexion injury, two a hyperextension injury, and two were not categorised.

Initial findings. The diagnosis of bilateral facet dislocation was initially missed in all 13 patients. Seven had head injuries and skull radiographs had been taken but none of the cervical spine. One patient with a back injury and Down's syndrome had no early radiographs. Eight patients had other significant injuries which may have distracted attention from the cervical spine.

In nine patients, the initial radiographs of the cervical spine were inadequate. In four patients, radiographs of the cervical spine were not initially taken as a cervical spine injury was not suspected. There were spondylotic changes in six of the spines.

Additional factors in the failure to make an early diagnosis were schizophrenia in one patient and epilepsy in another.

Only nine of the patients complained of pain in the neck; another had some interscapular pain. Ten of the patients had been admitted to hospital immediately after the injury: three were sent home and re-admitted only after they had become paralysed.

The hospital reports gave little information about the onset of pain, its distribution or severity or the range of cervical movement. In two patients the neck had not been examined. At the initial clinical examination 12 of 
the 13 patients had no abnormal neurological signs, and spinal-cord injury was suspected in only two, but at the thoracic level.

Progression of paralysis. In the records of nine patients there was evidence of the gradual development and progression of paralysis, but in the other four the first recorded change was complete paralysis (Fig. 1, Table I). Of the nine with gradual changes, seven developed paralysis in hospital and two at home; six had a history of transient symptoms immediately after injury. These changes were motor weakness and a 'funny' sensation in the lower limbs, which had settled rapidly.

Deterioration in these patients began with mild neurological signs such as hypo-aesthesia, altered reflexes, slightly reduced muscle power or muscular pain, cramps or spasms. The commonest pattern was motor weakness starting in one or both hands, with or without hypo-aesthesia, and progressing via increased motor weakness or bladder involvement to complete paralysis. Other patterns were seen (Table I). One patient who had been admitted because of a head injury initially developed generalised weakness of the upper limbs which then progressed distally. Another with generalised weakness and loss of sensation later developed urinary retention and then became completely paralysed.

In four patients the progression of paralysis had not been documented. The paralysis had occurred rapidly over six to 12 hours in three, but in the fourth, this had been difficult to assess because of multiple injuries.
The onset of paralysis was within six hours of the injury in three patients, from six to 24 hours in five and from 24 to 48 hours in four. In one patient, paralysis developed 17 days after the injury.

Radiology. Even after the diagnosis of paralysis the first cervical-spine radiographs failed to show the lower cervical spine in nine cases; in the other four no cervicalspine radiographs had been taken because neck injury was not suspected. The radiographic diagnosis was eventually made in nine cases on films taken with the shoulders pulled down. The other four were diagnosed on oblique views, a swimmer's view, tomography and myelography, respectively.

The dislocation was at $\mathrm{C} 6-\mathrm{C} 7$ in nine patients and at C5-C6 in four. One patient had dislocation at both C6$\mathrm{C} 7$ and at $\mathrm{C} 7-\mathrm{T} 1$.

All showed the radiological appearance of bilateral facet dislocation, with forward shift of 8 to $15 \mathrm{~mm}$ (mean 10.7), always more than or equal to half the anteroposterior diameter of the body of the vertebra. The sagittal diameter of the spinal canal at the level of dislocation, measured after reduction, varied from 15 to $21 \mathrm{~mm}$ (mean 18.15). There were associated fractures at the level of dislocation in eight patients, most commonly involving the facet. The radiographic changes of cervical spondylosis were seen in eight patients.

Management. Once the diagnosis of dislocation had been established skull traction was applied under local anaesthesia within six to eight hours. Weights of 10 to $20 \mathrm{lb}$

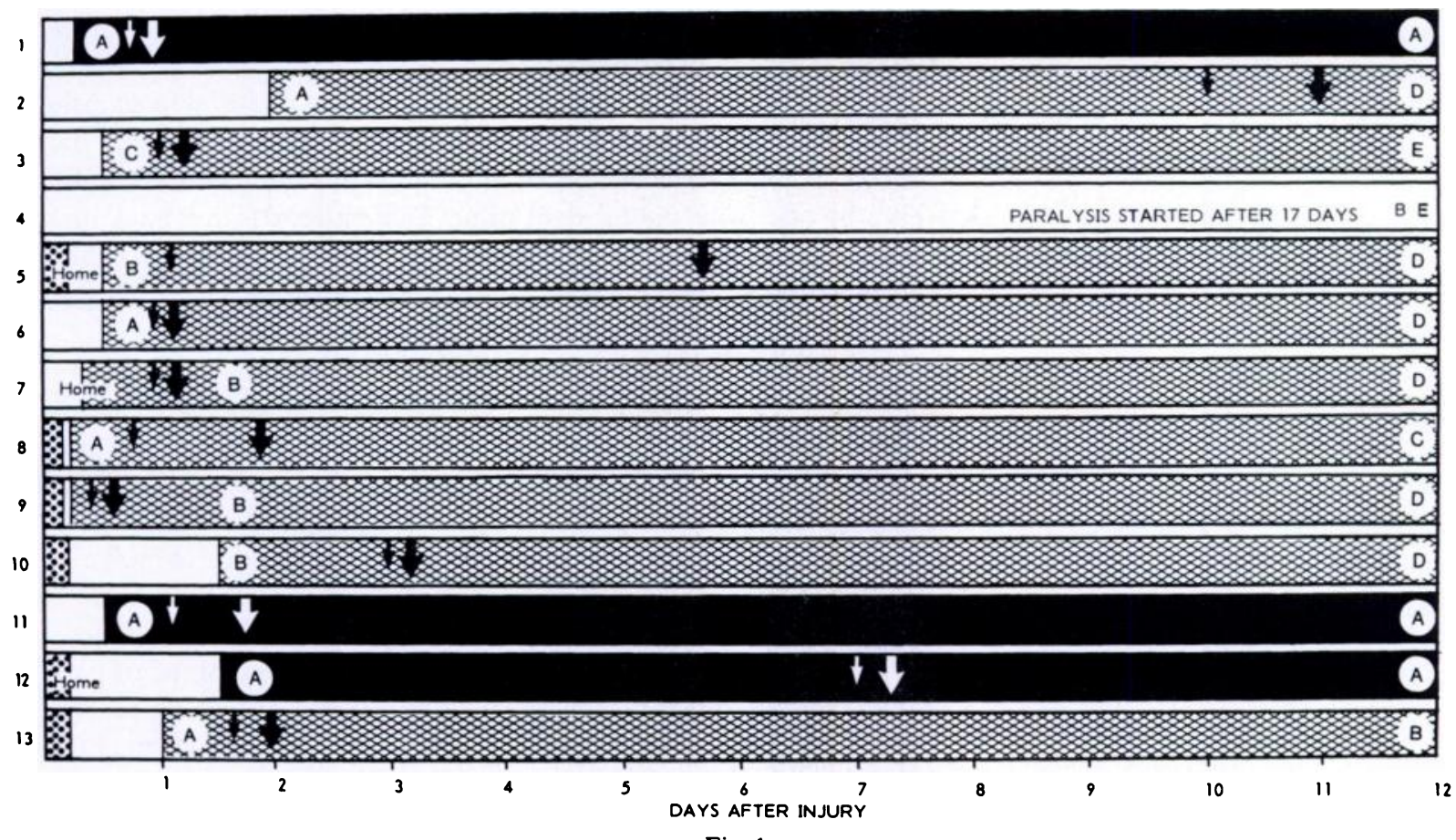

Fig. 1

Diagram to show the timing of the onset of paralysis, indicating transient symptoms (dotted), partial tetraparesis (hatched), complete tetraplegia (black), diagnosis made and reduction started (arrows). The worst Frankel grading in each case is shown on the left, and the final grading on the right. A, complete neurological lesion; B, sensory sparing only; C, sensory sparing and non-functional motor activity; D, sensory sparing and functional motor activity; E, normal functional activity (recovery). 
Table I. Development of tetraparesis in 13 patients with bilateral facet dislocation of the lower cervical spine

\begin{tabular}{|c|c|c|c|c|}
\hline \multirow[b]{2}{*}{ Case } & \multirow[b]{2}{*}{ Initial finding } & \multicolumn{3}{|l|}{ Progress $\ldots, \ldots . \quad \therefore \ldots$} \\
\hline & & Interval 1 & Interval 2 & Interval 3 \\
\hline 1 & No neurology & $\begin{array}{l}6 \text { hours } \\
\text { Tetraparesis }\end{array}$ & & \\
\hline 2 & No neurology & $\begin{array}{l}48 \text { hours } \\
\text { Postoperative weakness } \\
\text { of hand muscles* }\end{array}$ & $\begin{array}{l}10 \text { days } \\
\text { Tetraparesis }\end{array}$ & \\
\hline 3 & No neurology & $\begin{array}{l}18 \text { hours } \\
\text { Weakness of hand } \\
\text { muscles }\end{array}$ & $\begin{array}{l}12 \text { hours } \\
\text { Weakness of triceps and } \\
\text { hypo-aesthesia of hands }\end{array}$ & \\
\hline 4 & No neurology & $\begin{array}{l}17 \text { days } \\
\text { Weakness of both hands, } \\
\text { decreased movement of } \\
\text { right leg }\end{array}$ & $\begin{array}{l}7 \text { days } \\
\text { Recovered }\end{array}$ & $\begin{array}{l}15 \text { days } \\
\text { Tetraparesis }\end{array}$ \\
\hline 5 & Transient paralysis & $\begin{array}{l}8 \text { hours } \\
\text { Weakness and hypo- } \\
\text { aesthesia of left arm }\end{array}$ & $\begin{array}{l}24 \text { hours } \\
\text { Paralysis increased with } \\
\text { bladder involvement }\end{array}$ & \\
\hline 6 & No neurology & $\begin{array}{l}12 \text { hours } \\
\text { Tetraparesis }\end{array}$ & & \\
\hline 7 & Minor neurology & $\begin{array}{l}12 \text { hours } \\
\text { Tetraparesis }\end{array}$ & & \\
\hline 8 & Transient paralysis & $\begin{array}{l}4 \text { hours } \\
\text { Motor weakness and } \\
\text { abnormal sensation }\end{array}$ & $\begin{array}{l}16 \text { hours } \\
\text { Tetraparesis }\end{array}$ & \\
\hline 9 & Transient paralysis & $\begin{array}{l}5 \text { hours } \\
\text { Tetraparesis }\end{array}$ & $\begin{array}{l}6 \text { hours } \\
\text { Tetraparesis with bladder } \\
\text { involvement }\end{array}$ & \\
\hline 10 & Transient paralysis & $\begin{array}{l}72 \text { hours } \\
\text { Weakness of right hand }\end{array}$ & $\begin{array}{l}12 \text { hours } \\
\text { Weakness of right leg }\end{array}$ & $\begin{array}{l}12 \text { hours } \\
\text { Tetraparesis with bladder } \\
\text { involvement }\end{array}$ \\
\hline 11 & No neurology & $\begin{array}{l}5 \text { hours } \\
\text { Mild motor weakness of } \\
\text { all limbs }\end{array}$ & $\begin{array}{l}12 \text { hours } \\
\text { Weakness increased on } \\
\text { left side }\end{array}$ & $\begin{array}{l}24 \text { hours } \\
\text { Tetraparesis }\end{array}$ \\
\hline 12 & Transient paralysis & $\begin{array}{l}48 \text { hours } \\
\text { Weakness of hand } \\
\text { muscles }\end{array}$ & $\begin{array}{l}72 \text { hours } \\
\text { Bladder involvement }\end{array}$ & $\begin{array}{l}5 \text { days } \\
\text { Tetraparesis }\end{array}$ \\
\hline 13 & Transient paralysis & $\begin{array}{l}24 \text { hours } \\
\text { Bladder involvement }\end{array}$ & $\begin{array}{l}18 \text { hours } \\
\text { Tetraparesis }\end{array}$ & \\
\hline
\end{tabular}

* after splenectomy

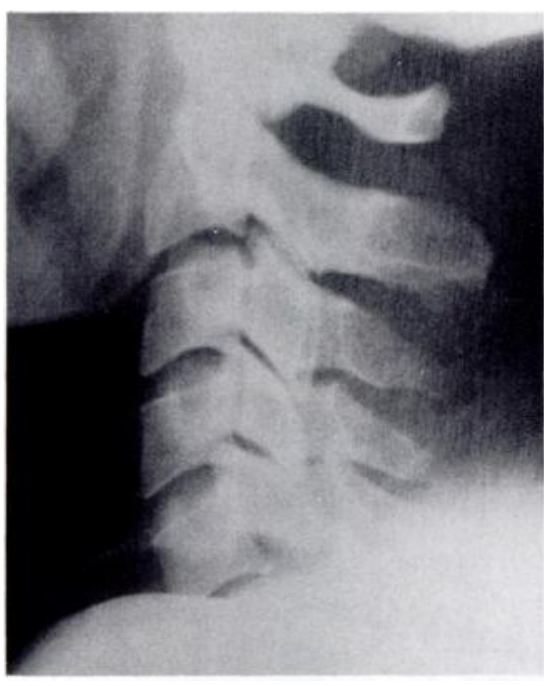

Fig. 2a

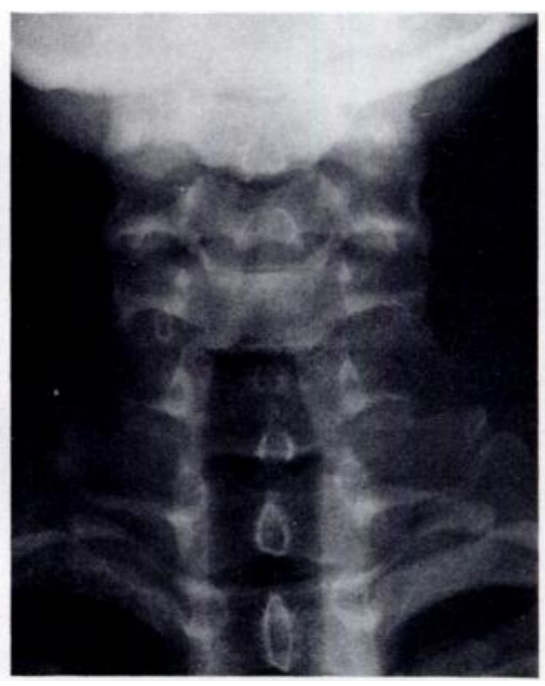

Fig. 2b

Missed bilateral facet dislocation - a) the lateral view shows the spine down to C5 only, but the facet dislocation at C5-C6 is just visible and b) the anteroposterior view shows increased distance between the spinous processes of $\mathrm{C} 5$ and $\mathrm{C6}$, with widening of the $\mathrm{C5}$-C6 intervertebral disc space. 
( 4.5 to $9.1 \mathrm{~kg}$ ) were maintained for six to eight weeks. Complete reduction was achieved in ten patients, and partial reduction in three. One patient required operative fusion for instability but sound bony ankylosis was achieved in all.

During their rehabilitation, eight patients showed neurological recovery by two or more grades (Frankel et al 1969), two showed some improvement, but three patients remained completely paralysed (Fig. 1). There was a tendency to better recovery in those patients who had been paralysed for a shorter period. The three patients whose dislocations had not been fully reduced (cases $2,4,8$ ), however, all showed substantial recovery.

\section{DISCUSSION}

We found records of only 13 patients who developed early progressive paralysis after bilateral facet dislocation. Other authors (Bohlman 1979; Shrosbree 1979; Osti, Fraser and Griffiths 1989) have not recorded this problem.

The mechanism of cervical dislocation has been demonstrated experimentally (Bauze and Ardran 1978). Force applied along the axis of the semi-flexed spine results in a series of changes: the posterior ligaments rupture, the facets slide upwards, the anterior longitudinal ligament is stripped and dislocation occurs. If the force continues to displace the vertebral body, the lamina will sweep across and transect the cord, but if the movement has been relatively slow and gentle the cord may not at first be damaged. This sequence is not just theoretical. It was described by several patients who were injured in a collapsing rugby scrum. They felt a click in the neck when the head struck the ground; when pressure continued there was an explosion of neck pain and the onset of paralysis.

In our series a hyperflexion mechanism was clear in nine cases, seven of them in falls down stairs. The forces involved were also of relatively minor severity in the road-traffic accidents and in the single sporting accident; a trampolinist landed on his trampoline, which would have absorbed much of the force of impact. This, and the lack of any severe associated injuries, suggests that the forces in these cases were not enough to damage the cord severely at the time of injury.

Nearly half the patients were female, while most admissions to the NSIC are male, and the dislocations were in an older age group than usual, with eight showing spondylotic changes. In such patients, it seems that bilateral facet dislocation may be produced by less severe forces without damaging the cord. Another factor may be that the average sagittal diameter of the spinal canal in our patients was $18.15 \mathrm{~mm}$, higher than normal (Braakman and Penning 1971).

At the primary injury, pain in the neck is not due to involvement of the cord, since it has no pain receptors. Pain is due to impingement or traction on the cervical nerves or joints; it may be present only when the head is moved. The transient feeling of paralysis reported by six of our patients could have been caused by the stretching of the nerve fibres.

The subsequent development of severe paralysis between six and 48 hours later in 12 patients is probably due to oedema of the spinal cord within the narrowed bony canal. Oedema carries a poor prognosis for spinalcord function (Koyanagi et al 1989) and may be followed by circulatory changes which result in a permanent cord lesion. A further factor is that bilateral facet dislocations are unstable (Beatson 1963; Bauze and Ardran 1978; Bohlman 1979) and any uncontrolled movement may cause further damage to the cord.

In our cases the diagnosis was missed because of lack of awareness that a severe cervical-spine injury could occur without paralysis, and with only mild or no pain in the neck. The subsequent development of abnormal neurological signs or symptoms in the hands, chest or lower limbs sometimes directed attention erroneously to a suspected head injury or a suspected thoracic spinal injury. Bohlman (1979) has previously reported these problems. Any blow to the head producing neck pain must produce a high index of suspicion of an injury to the cervical spine. Even greater vigilance and care are required in the presence of concussion or alcoholic intoxication (Ravichandran and Silver 1982; Toscano 1988). In such cases, radiographs are needed of the entire cervical spine (Grundy, Russell and Swain 1986).

Routine lateral radiographs (Fig. 2) show the upper and middle cervical vertebrae, but if the lower vertebrae are not clearly seen, dislocation can sometimes be suspected from careful study of the anteroposterior and lateral views (Ravichandran and Silver 1982). If there is any doubt, special views of the lower cervical spine must be taken under medical supervision. If available, CT or MR imaging is of value.

In our series, the cord was intact, or only slightly injured, immediately after the dislocation, and eight patients made a substantial recovery after neurological deterioration. Twelve of our patients developed paralysis at six to 48 hours after injury, and it seems that reduction within six hours would have given a good chance of complete preservation of neurological function.

It is interesting that three patients in whom reduction was not achieved nevertheless made some recovery. A few patients are known to have had bilateral facet dislocation with no significant spinal-cord damage. In these the diagnosis was established by radiography many weeks later. Management is difficult because the reduced spinal canal carries the risk of later cord damage with time or from trivial trauma (McMillan and Silver 1987).

Bilateral facet dislocations should be diagnosed and reduced as soon as possible after injury. Once paralysis has developed, the cord becomes swollen and oedematous, and the prognosis is much worse. Unnecessary 
morbidity could be avoided if all patients with suspected cervical-spine trauma were seen urgently at an appropriately staffed and equipped accident department where they can be properly examined, diagnosed and treated.

We wish to thank Mr I. Nuseibeh, Mr J. I. L. Bailey, Dr H. L. Frankel, and Mr B. G. Gardner for allowing us to discuss their cases.

No benefits in any form have been received or will be received from a commercial party related directly or indirectly to the subject of this article.

\section{REFERENCES}

Bauze RJ, Ardran GM. Experimental production of forward dislocation in the human cervical spine. J Bone Joint Surg [Br] 1978; 60B:239-45.

Beatson TR. Fractures and dislocations of the cervical spine. $J$ Bone Joint Surg [Br] 1963; 45-B:21-35.

Bohlman HH. Acute fractures and dislocations of the cervical spine: an analysis of three hundred hospitalized patients and review of the literature. J Bone Joint Surg [Am] 1979; 61-A:1119-42.

Braakman R, Penning L. Injuries of the cervical spine. Amsterdam: Excerpta Medica, 1971:172.
Evans DK. Reduction of cervical dislocations. J Bone Joint Surg [Br] $1961 ;$ 43-B :552-5.

Frankel HL, Hancock DO, Hyslop G, et al. The value of postural reduction in the initial management of closed injuries of the spine with paraplegia and tetraplegia. Paraplegia 1969; 7:179-92.

Grundy D, Russell J, Swain A. ABC of spinal cord injury. Br Med J 1986:292.

Koyanagi I, Iwasaki Y, Isu T, Akino M, Abe H. Significance of spinal cord swelling in the prognosis of acute cervical spinal cord injury. Paraplegia 1989; 27:190-7.

McMillan BS, Silver JR. Extension injuries of the cervical spine resulting in tetraplegia. Injury $1987 ; 18: 224-33$.

Osti OL, Fraser RD, Griffiths ER. Reduction and stabilisation of cervical dislocations. J Bone Joint Surg [ Br] 1989; 71-B:275-82.

Ravichandran G, Silver JR. Missed injuries of the spinal cord. Br Med $J$ 1982; 284:953-6.

Shrosbree RD. Neurological sequelae of reduction of fracture dislocations of the cervical spine. Paraplegia 1979; 17:212-21.

Toscano J. Prevention of neurological deterioration before admission to a spinal cord injury unit. Paraplegia $1988 ; 26: 143-50$.

Walton GL. A new method of reducing dislocation of cervical vertebrae. J Nerv Ment Dis 1893; 20:609-11. 